\title{
Ensino remoto no ensino de enfermagem: reflexões sobre o design instrucional na
}

\section{Pandemia da Covid-19}

\author{
Remote teaching in nursing teaching: reflections on instructional design in the Covid-19 Pandemic \\ La enseñanza a distancia en la enseñanza de enfermería: reflexiones sobre el diseño instruccional \\ en la pandemia de Covid-19
}

Recebido: 16/08/2021 | Revisado: 25/08/2021 | Aceito: 30/08/2021 | Publicado: 02/09/2021

\author{
Alessandra Conceição Leite Funchal Camacho \\ ORCID: https://orcid.org/0000-0001-6600-6630 \\ Universidade Federal Fluminense, Brasil \\ E-mail: alessandracamacho@id.uff.br \\ Vitória Meireles Felipe de Souza \\ ORCID: https://orcid.org/0000-0002-1129-6324 \\ Universidade Federal Fluminense, Brasil \\ E-mail: vifelipe@id.uff.br
}

\begin{abstract}
Resumo
Objetivo: descrever as estratégias de design instrucional no ensino remoto nas disciplinas de graduação em enfermagem em tempos de Pandemia. Métodos: Trata-se de um ensaio teórico de análise reflexiva sobre a importância do design instrucional no ensino remoto nas disciplinas de graduação em enfermagem com vistas à proposição de um ensino interativo. A análise reflexiva está pautada nas estratégias pedagógicas com vistas avaliação das atividades de forma interativa buscando a troca de conhecimentos. Resultados: como mediador do conhecimento o professor deve buscar conteúdos e atividades que visam o aprendizado colaborativo. Considerações Finais: O design instrucional deve ser construído constantemente e reavaliado com ampla utilização das ferramentas do ambiente virtual de aprendizagem.
\end{abstract}

Palavras-chave: Enfermagem; Pandemias; Coronavírus; Tecnologia; Educação.

\begin{abstract}
Objective: to describe instructional design strategies in remote teaching in undergraduate nursing disciplines in times of Pandemic. Methods: This is a theoretical essay of reflective analysis on the importance of instructional design in remote teaching in undergraduate nursing disciplines with a view to proposing an interactive teaching. Reflective analysis is based on pedagogical strategies with a view to evaluating activities in an interactive way, seeking the exchange of knowledge. Results: as a mediator of knowledge, the teacher must seek content and activities aimed at collaborative learning. Final Considerations: Instructional Design must be constantly built and re-evaluated with extensive use of the tools of the virtual learning environment.
\end{abstract}

Keywords: Nursing; Pandemics; Coronavirus; Technology; Education.

\section{Resumen}

Objetivo: describir estrategias de diseño instruccional en la enseñanza a distancia en disciplinas de pregrado en enfermería en tiempos de Pandemia. Métodos: Este es un ensayo teórico de análisis reflexivo sobre la importancia del diseño instruccional en la enseñanza a distancia en las disciplinas de enfermería de pregrado con miras a proponer una enseñanza interactiva. El análisis reflexivo se basa en estrategias pedagógicas con el fin de evaluar las actividades de forma interactiva, buscando el intercambio de conocimientos. Resultados: como mediador del conocimiento, el docente debe buscar contenidos y actividades orientadas al aprendizaje colaborativo. Consideraciones finales: El diseño instruccional debe construirse y reevaluarse constantemente con un uso extensivo de las herramientas del entorno de aprendizaje virtual.

Palabras clave: Enfermería; Pandemias; Coronavirus; Tecnología; Educación.

\section{Introdução}

A doença respiratória chamada COVID-19 foi denominada como uma pandemia em 11 de março de 2020, pela Organização Mundial da Saúde (OMS, 2020). Esta pandemia se espalhou no mundo, exigindo diversas formas para viver e sobreviver frente ao Coronavírus e impôs sua disseminação, contaminando e fazendo vítimas em vários países. Diante dessa 
realidade as medidas de isolamento e distanciamento social adotadas pelos países, inclusive o Brasil, por meio do confinamento com regras nem sempre rígidas para manter a população em casa, refletiu na paralisação de distintos serviços e atividades, sobretudo o processo de ensino-aprendizagem e as atividades presenciais (Camacho, Joaquim, Menezes \& Sant' Anna, 2020).

O Ministério da Educação, através da Portaria no 343, de 17 de março de 2020, publicou a substituição das aulas presenciais por aulas em meios digitais enquanto durar a pandemia do novo coronavírus denominado como SARS-CoV-2. As instituições de ensino definiram as disciplinas de maneira remota, assim, ocorreu a disponibilização de ferramentas aos alunos de maneira a permitir o acompanhamento dos conteúdos ofertados bem como a realização de avaliações durante o período da autorização (Ministério da Educação, 2020).

Com essas condições vigentes as instituições de ensino superior no país realizaram seus respectivos planejamentos de retorno das atividades acadêmicas e administrativas de forma remota dando a oportunidade de discussões sobre essa modalidade de ensino e de novas experiências voltadas para a capacitação do professor (Camacho, 2020). Nesse contexto emergiu uma configuração do processo de ensino-aprendizagem denominada Educação Remota, isto é, práticas pedagógicas mediadas por plataformas digitais, como aplicativos com os conteúdos, tarefas, notificações e/ou plataformas síncronas e assíncronas como o Teams (Microsoft), Google Classroom, Google Meet, Moodle e Zoom (Alves, 2020).

Além disso, sugiram outros problemas como a: ausência de computadores com os dispositivos móveis para acessar a rede internet; ausência de experiência com a interface das plataformas utilizadas nos encontros virtuais; a dificuldade em mediar as atividades que seguem a sequência prevista para as aulas presenciais, exigindo conhecimento e estratégias para ensinar os conteúdos.

Nesse contexto, as universidades criaram/adquiriram plataformas específicas para efetuação das aulas remotas, como por exemplo, o Google Classroom (plataforma mais usada na educação básica e no ensino superior inclusive público) (Alves, 2020).

Diante dessa perspectiva, o mundo está em constantes mudanças e de incertezas. A partir disso, existe a dificuldade na compreensão do que empreender com essa nova dinâmica do ensino remoto que ruma para o ensino híbrido. No entanto, algumas universidades estão optando pelo ensino remoto em virtude da elevada vigência de casos do novo coronavírus SARSCoV-2 em alguns estados do Brasil. Desse modo, tudo muda rápido e informações se tornam obsoletas em uma velocidade impressionante. Com essas colocações, destaca-se que seja o momento de descrever como aprendizes contínuos com aprendizagem centrada no discente, cuja presença materializa a ideia do aprender de ambas as partes: o professor e o discente.

Portanto, as estratégias de um bom delineamento do design instrucional sobre a disciplina remoto ministrada pelo docente de enfermagem no curso de graduação em tempos de pandemia, torna-se preponderante para que ocorra uma aprendizagem colaborativa e interativa fazendo com que ambas as partes docente e discente busquem conhecimentos de forma contínua. A vista disso, o presente artigo possui como objetivo descrever as estratégias de design instrucional no ensino remoto nas disciplinas de graduação em enfermagem em tempos de Pandemia.

\section{Metodologia}

Trata-se de um ensaio teórico de análise reflexiva sobre a importância do design instrucional no ensino remoto nas disciplinas de graduação em enfermagem com vistas à proposição de um ensino interativo. A análise reflexiva está pautada nas estratégias pedagógicas com vistas a avaliação das atividades de forma interativa buscando a troca de conhecimentos. Como mediador do conhecimento, o professor deve buscar conteúdos e atividades que visam o aprendizado colaborativo (Miranda, 2017). 
Destaca-se o Ambiente Virtual de Aprendizagem (AVA) em sua centralidade que disponibiliza vários aplicativos para o desenvolvimento do ensino remoto visando a interatividade e a criatividade através das atividades assíncronas (fóruns de discussões; vídeos; leitura de artigos entre outros) e as atividades síncronas (aulas, palestras e lives) (Vasconcelos, Jesus \& Santos, 2020, Salvador et al, 2017).

A grande vantagem do Ambiente Virtual de Aprendizagem (AVA) no ensino remoto é a otimização do tempo livre proporcionando um aprendizado de acordo com a demanda e motivação do discente atendendo a estratégia neste momento de pandemia. O conteúdo teórico da disciplina remoto deve ser especificado por datas e título das aulas de acordo com o cronograma da disciplina para melhor visualização discente. As avaliações devem ser desenvolvidas ao longo da disciplina através da participação na sala de aula virtual de forma assíncrona; participação nas aulas remoto de forma síncrona e a construção de atividades interativas (Moreira, Henriques \& Barros, 2020).

Para melhor compreensão, este artigo de reflexão está organizado nos seguintes aspectos: o design instrucional no ensino remoto e estratégias pedagógicas com vistas avaliação das atividades interativas buscando a troca de conhecimentos.

\section{Resultados e Discussão}

\section{O design instrucional no ensino remoto}

O design instrucional está relacionado com a tecnologia usada sendo a base para a prática, ou seja, a ação de comunicar para que o estudante seja instruído a aprender algo, de maneira que o seu conhecimento seja avaliado ao final do processo, em forma de desempenho. Nota-se que a instrução está inserida no processo educacional, sendo uma parte do complexo processo de aprendizado que o estudante necessita para poder atingir o conhecimento desejado (Macedo \& Bergmann, 2018, Araújo \& Duarte, 2018).

Antes de se partir diretamente para o lançamento das metodologias, técnicas ou atividades é importante que o docente elabore o design instrucional referente à disciplina. Para isso é preciso aliar os recursos educacionais, por meio de suas plataformas e sistemas, aos projetos pedagógicos, envolvendo os conteúdos, ementas, técnicas e atividades que melhor se adequem aos objetivos de cada disciplina ou curso (Dornelas, Campos \& Martin, 2020, Castro \& Liska, 2021).

O design instrucional deve coadunar com as atividades atribuídas na disciplina remota de forma que atenda a alguns aspectos relevantes como: adequação da linguagem dos conteúdos de forma clara e que busque o diálogo, disponibilidade de e-books gratuitos, mídias interativas, recursos didáticos visando a interatividade. Observa-se ainda a importância do acompanhamento do trabalho do professor/conteudista, para o levantamento e análise de necessidades de instrução e ensino, colaborando com a autoria na programação de estratégias de aprendizagem e avaliações (Macedo \& Bergmann, 2018, Moura, Ziviani \& Oliveira, 2016).

A modalidade de ensino remoto na educação em saúde tem por finalidade o de facilitar o processo de aprendizagem através de um design instrucional de promover o engajamento discente, a fim de potencializar a sua participação e o aprendizado. Assim, torna-se essencial elaboração na disciplina uma "ambientação" promovendo a apresentação da disciplina, o conhecimento do cronograma com conteúdos explicativos que serão disponibilizados para que os discentes compreendam a dinâmica do ambiente virtual de aprendizagem. Neste item de ambientação se disponibiliza: o cronograma e o plano remoto da disciplina; se necessário vídeos explicativos sobre a apresentação da disciplina e de forma muito didática sobre como o aluno deve acessar e estudar no ambiente virtual de aprendizagem (Salvador et al, 2016 Diesel, Baldez \& Martins, 2017).

Ainda assim, para melhor elucidação os demais conteúdos da disciplina devem ser organizados por datas de acordo com o plano remoto da disciplina e utilizando ferramentas interativas de aprendizagem. A partir disso, o planejamento fica voltado para a disponibilidade de conteúdos que possibilitassem diminuir dúvidas como destaque ao design instrucional nestes 
aspectos para melhor compreensão do Ambiente Virtual de Aprendizagem (AVA).

Nota-se a importância da criação de tópicos para que os discentes possam interagir e retirar as dúvidas de forma assíncrona sobre as aulas remotas e o próprio material de estudo. Essas atividades planejadas e implementadas devem ser pautadas no Plano Pedagógico Institucional da Universidade que tem estruturado suas metodologias pelo paradigma da modernidade, na qual as sociedades atuais estão a exigir, cada vez mais, a participação de cidadãos não somente qualificados para o trabalho, mas principalmente aptos a refletir e produzir novos conhecimentos acerca de sua prática profissional.

Destaca-se que o aluno desenvolve a aprendizagem cooperativa, a pesquisa em grupo, a troca de resultados. A interação bem-sucedida aumenta a aprendizagem no ambiente virtual de aprendizagem. Para tanto, os objetivos de aprendizagem devem ser esclarecidos para que a troca de conhecimentos possa se consolidar de forma mútua e devem ser bem elucidados pelo professor.

Soma-se a isso que durante a vigência da disciplina pode ocorrer a necessidade de flexibilização de horários, gravação das transmissões online das aulas para que os alunos possam apresentar acesso dos conteúdos em outros momentos. Esses aspectos fornecem maior oportunidade de flexibilidade no controle de frequência dos alunos através do acesso dos mesmos no ambiente virtual de aprendizagem não somente de forma síncrona, mas também assíncrona.

\section{Estratégias pedagógicas com vistas a avaliação das atividades interativas buscando a troca de conhecimentos}

Com relação às várias possibilidades de técnicas e metodologias voltadas para o ensino não presencial é importante destacar que as atividades podem se configurar como síncronas ou assíncronas, a partir de uma classificação do tempo da comunicação (Dornelas, Campos \& Martin, 2020, Arruda, 2020).

Nas atividades síncronas, há o requisito que ambas as partes (aluno e professor) estejam disponíveis ao mesmo tempo, possibilitando maior interação, em que o professor pode estimular a participação interativa do aluno, bem como condições para a retirada de dúvidas em tempo real do aluno. Já na modalidade assíncrona, não há nenhuma exigência quanto ao tempo, permitindo maior liberdade e flexibilidade tanto para os professores, quanto para os alunos. Isso dá condições para que ambos possam planejar de forma mais adequada o tempo, local e horário de trabalho e estudo (Dornelas, Campos \& Martin, 2020, Piffero, Coelho, Soares \& Roehrs, 2020).

Aponta-se como uma oportunidade de aproveitar esse momento para criar fóruns de debates a fim de discutir as trilhas que podem ser construídas para pensar um processo educacional de qualidade, na rede pública e privada durante a pandemia e pós-COVID-19, delineando uma perspectiva educacional que possibilitem aos professores e estudantes discutirem juntos estratégias que viabilizem uma discussão crítica do momento que estamos vivendo, analisando as consequências para vida das pessoas, bem como as proposições de como ensinar para uma geração que interagem com as tecnologias digitais para se comunicar, com vistas a aprendizagem colaborativa (Alves, 2020).

Como maneira de verificação do processo de ensino aprendizagem contínua é possível identificar formas de contato efetivas pelo registro das funcionalidades do ambiente virtual de aprendizagem, como a participação e discussões nas aulas remoto síncrona e nas atividades assíncronas, nos feedbacks das atividades e nas contribuições dentro do AVA (disponíveis no mural, nos fóruns de debates e nas postagens das atividades) (Camacho, 2020).

$\mathrm{O}$ ensino remoto deve ser visto como aliado no curso de graduação em Enfermagem e não como uma atividade substitutiva neste período de Pandemia. O ensino remoto como método não consiste apenas em apresentação de textos, vídeos, fóruns e outros aplicativos, mas deve ser visto como uma maneira de analisar a motivação e o comportamento do aluno diante do desafio do aprendizado colaborativo (Teixeira, Lage, Junior, Corradi, \& Oliveira, 2020).

A construção da interatividade no ensino remoto é fundamental para o planejamento contínuo do AVA através do uso de ferramentas e aplicativos na disciplina de forma remota frente ao isolamento social imposto pela pandemia. Nesse contexto, 
buscando a interatividade, o docente precisa oportunizar atividades interativas, cujos discentes da graduação em Enfermagem devem construir materiais educativos de acordo com a temática de abordagem de estudo da disciplina de maneira remota.

Acrescenta-se que visando a autonomia do discente de enfermagem, torna-se essencial a busca de conexões articuladas dos conteúdos para que o estudante seja o centro da aprendizagem, mantendo o foco no conteúdo abordado preparando-o para detectar e articular informações confiáveis, além de trabalhar a competência para continuar aprendendo de forma assíncrona.

Diante isso, é preciso uma análise crítica e reflexiva no ensino remoto, exigindo criatividade dos docentes para promoção de discussões junto aos discentes sobre o conteúdo. O trabalho remoto exige dos professores: horário, dedicação, vídeos explicativos, interação e adequação do ambiente virtual de aprendizagem. Além disso, exige diversidade das atividades nesse tipo de formato (Bastos et al, 2020).

Neste sentido, a enfermagem deve compartilhar da perspectiva de saúde como qualidade de vida e proteção frente ao SARS-CoV-2, da participação e do controle social, da integralidade das ações de saúde individual e coletiva e, por fim, da inclusão à educação (Costa et al, 2020). O ensino remoto precisa ser inclusivo respeitando as diferenças, propondo medidas que assegurem melhoria da qualidade da educação, o investimento com ampla formação dos educadores, a previsão e provisão de recursos materiais e humanos.

O docente pode contribuir para que o discente desenvolva as competências, numa interrelação inseparável de conhecimentos (conteúdos), e habilidades para investigar a natureza complexa dos fenômenos do contexto da era digital. Para tanto, deve-se primar pela atenção ao conteúdo, mas também estabelecer a empatia e cuidado nas relações com os seus alunos, promovendo incessantemente o diálogo aberto e acolhedor. Espera-se ainda que seja capaz de promover a confiança, estímulo e motivação do educando (Dornelas, Campos \& Martin, 2020).

As atividades avaliativas nos encontros síncronos e assíncronos com os alunos devem possuir a oportunidade de externar as dúvidas e possibilidades de troca de conhecimentos. Estes alunos inclusos no AVA precisam ser capazes de apresentar a possibilidade de atuar ativamente nas atividades propostas da disciplina que podem ser compostas por trabalhos interativos em grupo; chats realizados nos encontros síncronos para debates sobre o conteúdo da disciplina, fóruns para discussão sobre o conteúdo programático, informativos, além de trabalhos previamente programados de maneira assíncrona.

Nesse cenário, através das ferramentas a interatividade entre professores e alunos podem construir relações ricas de troca de conhecimento. Nesta perspectiva os conteúdos desenvolvidos e postados pelos professores por meio de textos, vídeos e inserção de anexos, permitem que as tarefas possam ser criadas na hora ou programadas, tornando-a perfeita tanto para as disciplinas de curta ou de longa duração. Os alunos então são convidados a responder as tarefas, sendo avaliados pelo professor pelo próprio ambiente virtual de aprendizagem (Camacho, Joaquim, Menezes, \& Sant' Anna, 2020).

Todas as atividades propostas devem fazer parte integrante da avaliação dos discentes na disciplina visando o desenvolvimento de habilidades e competências de acordo com o Projeto Político Pedagógico do curso.

A avaliação deve ocorrer durante todo o desenvolvimento da disciplina de maneira remota com ênfase no aprendizado colaborativo trazendo novas informações, demonstrando conexões e propondo soluções com justificativa das ideias apresentadas. O professor deve observar, se houve a compreensão adequada das informações apresentadas e é importante fazer as intervenções necessárias sempre voltado para a interatividade.

Cabe ainda destacar que ao final da disciplina remota é imprescindível realizar uma avaliação com vistas a adequação contínua do planejamento da disciplina remoto. Como principal implicação para pesquisas futuras deve-se criar a possibilidade de debates inclusivos sobre o ensino remoto na graduação em Enfermagem não somente para o momento que a sociedade está vivendo, mas que viabilizem diretivas importantes para um ensino híbrido e integrado com vistas a reflexões positivas (Camacho, 2020). 
Diante desta realidade sobre a pandemia do COVID-19, recomenda-se que o docente traga intervenções significativas que promovam reflexões, de modo que cada aluno, usufruindo dos recursos disponíveis no ensino remoto, possa compor cenários em sintonia com os elementos próprios do conteúdo abordado na disciplina e consiga transformar sua aprendizagem em experiências positivas.

Sem dúvida, cabe destacar o que se estabeleceu sobre o ensino remoto: a amplitude das opções tecnológicas e de conteúdo; a importância do discente perceber a responsabilidade sobre o seu processo de aprendizagem e o uso consciente do ambiente virtual de aprendizagem; melhoria nas formas de aprender e nas competências técnicas dos estudantes com a utilização das ferramentas colaborativas; incentivo à colaboração, pois as ferramentas sociais utilizadas possibilitaram aos estudantes oportunidades de colaboração e de comunicação com colegas e professores; prática de atividades que buscam a cognição - pesquisa, leitura, análise e criação de conteúdos digitais como por exemplo folders e blogs interativos; e compartilhamento de novas ferramentas para auxiliar nas suas atividades de aprendizagem.

Visando desenvolvimento crítico e reflexivo do futuro profissional enfermeiro em que o ensino deve sempre ser centrado no aluno. É uma atividade de incentivo contínuo ao estudante de enfermagem considerando suas perspectivas no sentido de desenvolver sua capacidade de decisão nas atividades propostas.

\section{Conclusão}

Com o objetivo descrever as estratégias de design instrucional no ensino remoto nas disciplinas de graduação em enfermagem em tempos de pandemia da COVID-19, torna-se possível vislumbrar a importância da interatividade entre o professor e o discente no transcurso da disciplina para que a mesma possa ocorrer de forma visível com o planejamento remoto disposto no seu planejamento. Além disso, a disponibilidade do docente de feedback das atividades ao discente, deve ser uma constante que coadune com a proposta pedagógica das aulas ministradas visando interatividade e um aprendizado colaborativo.

Como contribuição relevante deste artigo, destaca-se a possibilidade de buscar a interatividade na educação remota nos seguintes aspectos: continuidade do planejamento; o docente como medidor do conhecimento; w adequação do ambiente virtual de aprendizagem com as necessidades atuais do ensino remoto.

Sugere-se uma atenção diferenciada aos discentes em situação de vulnerabilidade social no ensino remoto para que o mesmo, seja inclusivo dando a oportunidade de integrar conhecimentos com a realidade e não ampliando cada vez mais as desigualdades. Como recomendação relevante há a importância do estabelecimento de estratégias de ensino articuladas com o conteúdo programático da disciplina através das ferramentas disponíveis no ambiente virtual.

\section{Referências}

Alves, L. (2020). Remote education: between illusion and reality. Interfaces Científicas, 8(3):348-365.

Araújo, D., \& Duarte, S.L.O. (2018). Reflexão sobre o contexto da educação a distância e a importância da ação do design instrucional no ambiente virtual de aprendizagem. CIET: EnPED. https://cietenped.ufscar.br/submissao/index.php/2018/article/view/904/181.

Arruda, E.P. (2020). Educação remota emergencial: elementos para políticas públicas na educação brasileira em tempos de Covid-19. Em Rede- Revista de Educação a Distância, 7(1), 257-275.

Bastos, M.C. et al. (2020). Emergency remote teaching in nursing graduation: experience report during covid-19. Rev Min Enferm, $24:$ - 1335.

Brasil. Ministério da Educação (BR). (2020). Portaria n 343, de 17 de Março de 2020 que dispõe sobre a substituição das aulas presenciais por aulas em meios digitais enquanto durar a situação de pandemia do Novo Coronavírus - COVID-19. Brasília: DF. https://www.in.gov.br/en/web/dou/-/portaria-n-343-de-17-demarco-de-2020-248564376

Camacho, A.C.L.F. (2020). Editorial: Remote teaching in times of the COVID-19 pandemic: New experiences and challenges. Online Braz J Nurs, 19(4). http://www.objnursing.uff.br/index.php/nursing/article/view/6475/pdf-pt

Camacho, A.C.L.F., Joaquim, F.L., Menezes, H.F., \& Sant' Anna, R.M. (2020). Tutoring in distance education in times of COVID-19: relevant guidelines. Research, Society and Development, 9(5)e30953151. 
Research, Society and Development, v. 10, n. 11, e309101119467, 2021

(CC BY 4.0) | ISSN 2525-3409 | DOI: http://dx.doi.org/10.33448/rsd-v10i11.19467

Castro, A.C., Liska, G.J.R. Contribuições do design instrucional na gestão do ensino superior durante a pandemia da COVID-19. Anais do Congresso Nacional Universidade, EAD e Software Livre, 2(11): 1-6.

Costa, R., et al. (2020). Nursing teaching in covid-19 times: how to reinvent it in this context?. Texto \& Contexto Enfermagem, 29 :e20200202.

Diesel, A., Baldez, A.L.S., \& Martins, S.N. (2017). Os princípios das metodologias ativas de ensino: uma abordagem teórica. Revista Thema,14(1), 268-288.

Dornelas, M.A., Campos, C.A., \& Martins, V.L. (2020). Ensino remoto na pandemia: proposta de design instrucional a partir de estilos de aprendizagem. Brazilian journal of policy and development: BRjpd, 2(4):118-141.

Macedo, C.C., \& Bergmann, J.C.F. (2018). O design instrucional e o design educacional no campo da EAD: conceito e prática. ABED: São Paulo http://www.abed.org.br/congresso2018/anais/trabalhos/9726.pdf

Miranda, A.P. (2017). Análise crítica-reflexiva na utilização da metodologia ativa. Enfermagem Brasil, 16(3): 182-189.

Moreira, J.A.M., Henriques, S., \& Barros, D. (2020). Transitando de um ensino remoto emergencial para uma educação digital em rede, em tempos de pandemia. Dialogia, (34): 351-364.

Moura, D., Ziviani, F \& Oliveira, L.C.V. Utilização do design instrucional em curso EAD: análise do ambiente virtual de aprendizagem do curso técnico à distância de uma instituição pública de ensino. Educação \& Tecnologia, 21(1): 1-11.

OMS World Heath Organization. (2020). Coronavirus disease 2019 (COVID-19): Situation Report -51. Geneva (CH). https://www.who.int/docs/defaultsource/coronaviruse/situation-reports/20200311-sitrep-51-covid-19.pdf?sfvrsn=1ba62e57_10

Piffero, E.L.F., Coelho, C.P., Soares, R.G., \& Roehrs, R. Metodologias ativas e o ensino remoto de biologia: o urso de recursos online para aulas síncronas e assíncronas. Research, Society and Development, 9(10): e719108465.

Salvador et al. (2017). Objeto e ambiente virtual de aprendizagem: análise de conceito. Rev Bras Enferm, 70(3):599-606

Teixeira, P.G., Lage, E.M., Junior, M.D.C., Corradi, W.J.B., \& Oliveira, C.L. (2020). The discipline primary attention to women's health, in the UFMG medicine course, mediated by technology. EmRede, 7(1): 177-93.

Vasconcelos, C.R.D., Jesus, A.L.P., \& Santos, C.M. (2020). Ambiente Virtual de Aprendizagem (AVA) na Educação a Distância (EAD): um estudo sobre moodle. Brazilian Journal of Development, 6(3): 15545-15557. 